\title{
A new approach to the silica gel surface : characterization of different surface regions by 29Si magic angle spinning NMR relaxation parameters and consequences for quantification of silica gels by NMR: characterization of different surface regions by silicon-29 magic angle spinning NMR relaxation parameters and consequences for quantification of silica gels by NMR
}

\author{
Citation for published version (APA): \\ Pfleiderer, B., Albert, K., Bayer, E., Ven, van de, L. J. M., Haan, de, J. W., \& Cramers, C. A. M. G. (1990). A new \\ approach to the silica gel surface: characterization of different surface regions by 29 Si magic angle spinning \\ NMR relaxation parameters and consequences for quantification of silica gels by NMR: characterization of \\ different surface regions by silicon-29 magic angle spinning NMR relaxation parameters and consequences for \\ quantification of silica gels by NMR. Journal of Physical Chemistry, 94(10), 4189-4194. \\ https://doi.org/10.1021/j100373a057
}

DOI:

10.1021/j100373a057

Document status and date:

Published: 01/01/1990

\section{Document Version:}

Publisher's PDF, also known as Version of Record (includes final page, issue and volume numbers)

\section{Please check the document version of this publication:}

- A submitted manuscript is the version of the article upon submission and before peer-review. There can be important differences between the submitted version and the official published version of record. People interested in the research are advised to contact the author for the final version of the publication, or visit the DOI to the publisher's website.

- The final author version and the galley proof are versions of the publication after peer review.

- The final published version features the final layout of the paper including the volume, issue and page numbers.

Link to publication

\section{General rights}

Copyright and moral rights for the publications made accessible in the public portal are retained by the authors and/or other copyright owners and it is a condition of accessing publications that users recognise and abide by the legal requirements associated with these rights.

- Users may download and print one copy of any publication from the public portal for the purpose of private study or research.

- You may not further distribute the material or use it for any profit-making activity or commercial gain

- You may freely distribute the URL identifying the publication in the public portal. 


\title{
A New Approach to the Sillica Gel Surface. Characterization of Different Surface Regions by ${ }^{29}$ Si Magic Angle Spinning NMR Relaxation Parameters and Consequences for Quantification of Sllica Gels by NMR
}

\author{
B. Pfleiderer, K. Albert, E. Bayer, \\ Institut für Organische Chemie, Auf der Morgenstelle 18, D-7400 Tübingen, F.R.G.
} L. van de Ven, J. de Haan,* and C. Cramers

Laboratory for Instrumental Analysis, Eindhoven University of Technology, P.O. Box 513, 5600 MB Eindhoven. The Netherlands (Received: February 2, 1989; In Final Form: September 26, 1989)

\begin{abstract}
Native and some monofunctionally derivatized silica gels have been investigated by ${ }^{29} \mathrm{Si}$ CP MAS NMR spectroscopy with pulse and with cross-polarization (CP) excitation. Contact time variation experiments for some native materials yield results for the siloxane $\left(\mathrm{Q}^{4}\right)$ groups which cannot be described with a single set of $T_{\mathrm{HSi}}$ and $T_{1 \rho \mathrm{H}}$ values. Quantitative analyses of such silicas with $\mathrm{CP}$ excitation require $\mathrm{CP}$ curves as standards. For these samples $T_{1 \mathrm{Si}}$ values measured with pulse excitation differ from those obtained by CP excitation. $T_{1 \mathrm{pH}}$ values depend on the contact time, selected for the experiment. Moreover, multiexponential $T_{1 \mathrm{Si}}$ analyses for $\mathrm{Q}^{3}$ and $\mathrm{Q}^{4}$ reveal that the longitudinal relaxation process of native silica gels generally can be separated into at least three different processes, each with its characteristic average value for $T_{1 \mathrm{~s} \text { : }}$. Explanations for $\mathrm{CP}$ behavior and $T_{1 \mathrm{Si}}$ inhomogeneities are offered in terms of different forms of coexistence in silica gels of relatively mobile amorphous regions. Implications of these results for quantification of surface groups of silicas with cross-polarization MAS NMR are discussed.
\end{abstract}

\section{Introduction}

Solid-state NMR, especially of ${ }^{29} \mathrm{Si}$, has almost developed into a routinely applied technique for the analysis of native and derivatized silica gels. After the first pioneering publication of Maciel and co-workers, ${ }^{1}$ many papers appeared on the subject. Some of those dealt specifically with qualitative aspects ${ }^{2}$ and others with the problems of obtaining quantitative results. ${ }^{3}$

The usual method of signal excitation in solid-state ${ }^{29} \mathrm{Si}$ MAS NMR of silica gels and derivatives is cross polarization. ${ }^{4}$ An alternative method consists of "classical" Bloch pulse excitation. Its use in the analysis of silica gels was advocated by Fyfe et al., 6 but the example has seen little further development. This is probably due to prohibitively long longitudinal relaxation times of ${ }^{29} \mathrm{Si}$, requiring excessively long pulse interval times to ensure quantitatively dependable results.

One obvious advantage of cross polarization $(C P)$ with respect to pulse excitation is time gain because interval times are now governed by longitudinal relaxation times of ${ }^{1} \mathrm{H}$ rather than of ${ }^{29} \mathrm{Si}$. This is true for those ${ }^{29} \mathrm{Si}$ nuclei which are in close contact (maximally four bonds away) with protons. This situation usually prevails for those regions of the silica gel close to the external surfaces, including pore surfaces. For this reason, cross-polarization excitation is the method of choice in the investigation of silica gels because of its surface selectivity. In the present study we are interested primarily in the properties of the silica gel surface.

It is known from chromatographic experiments that silicas of different sources may vary greatly in properties and that even

(1) Maciel, G. E.; Sindorf, D. W. J. Am. Chem. Soc. 1980, 102, 7606 (2) (a) Maciel, G. E.; Sindorf, D. W.; Bartuska, V. J. J. Chromatogr. 1981 205, 438. (b) Sindorf, D. W.; Maciel, G. E. J. Am. Chem. Soc. 1983, 105 3767. (c) Rudzinski, W. E.; Montgomery, T. L.; Frye, J. S.; Hawkins, B. L. Maciel, G. E. J. Catal. 1986, 98, 444. (d) Bayer, E.; Albert, K.; Reiners, J.; Nieder, M.: Müller, D. J. Chromatogr. 1983, 264, 197. (e) Claessens, H. A. de Haan, J. W.; van de Ven, L. J. M.; de Bruyn, P. C.; Cramers, C. A. J. Chromatogr. 1988, 436, 345.

(3) (a) Sindorf, D. W.; Maciel, G. E. J. Phys. Chem. 1982, 86, 5208. (b) Sindorf, D. W. Maciel, G. E. J. Phys. Chem 1983, 87,5516 . (c) Sindorf, D. W.: Maciel, G. E. J. Am. Chem. Soc. 1983, 105, 1487

(4) Pines, A.; Gibby, M. G.; Waugh, J. S. J. Phys. Chem. 1973, 59, 569

(5) Claessens, H. A.: van de Ven, L. J. M.; de Haan, J. W.; Cramers, C. A. J. High Resolut Chromatogr. Chromatogr. Commun. 1983, 6, 433. 277 .

(6) Fyfe, C. A.; Gobbi, G. C.; Kennedy, G. J. J. Phys. Chem. 1985, 89, batch-to-batch variations are quite common. ${ }^{5}$ In the present paper, it is shown that such variations exist also for CP characteristics of silica gel surfaces. The dynamic behavior of these, characterized by $T_{\mathrm{HSi}}, T_{1_{\rho} \mathrm{H}}$, and $T_{1 \mathrm{Si}}$ values, will be described and some of the possible reasons for the batch-to-batch differences will be discussed.

The primary aim of our investigation was to improve the quantitative aspects of solid-state ${ }^{29} \mathrm{Si}$ MAS NMR of silicas, in particular with $\mathrm{CP}$ excitation.

An important spin-off of the present results is that we obtained some silica gel CP curves which cannot be described in terms of one $T_{\mathrm{HSi}}$ and one $T_{1 \rho \mathrm{H}}$ value. This happened in particular for the signals of $\mathrm{Q}^{4}$ silicon atoms (carrying no hydroxyl groups) after the samples had undergone acid pretreatment. The phenomenon is tentatively ascribed to the existence of (small) polycrystalline domains (possibly $\beta$-tridymite). It will be further shown that, in particular with $C P$ excitation, the ${ }^{29} \mathrm{Si}$ magnetization of $Q^{3}$ and $\mathrm{Q}^{4}$ does not decay simply according to a single-exponential function but rather according to a curve implying the presence of two kinds of silicon nuclei. One kind has a $T_{1 \mathrm{Si}}$ value of $\mathrm{ca} .25-40 \mathrm{~s}$, the other kind of ca. $0.2 \mathrm{~s}$. Moreover, there seems to be a rather efficient exchange between the two kinds of silicon nuclei (time constant $0.7 \pm 0.25$ ) in spite of the isotopic dilution of ${ }^{29} \mathrm{Si}$ nuclei. Finally, multiexponential analysis of pulse-excited inversion-recovery MAS NMR signals of $\mathrm{Q}^{3}$ and $\mathrm{Q}^{4}$ indicates the presence of at least three different types with quite different relaxation rates.

\section{Experimental Section}

The sources of the commercially available basis silica gels were Lichrosorb (Merck, Darmstadt, FRG), Alfa products (Alfa products, Danvers, MA), Zorbax (Du Pont, Wilmington, DE), Nucleosil (Macherey-Nagel, Düren, FRG), Cab-O-Sil (Cabot, Tuscold, II), and Hypersil (Shandon, Runcorn, UK). Monofunctional derivatives were synthesized according to known procedures. ${ }^{2 \mathrm{~d}}$

The solid-state ${ }^{29} \mathrm{Si}$ NMR measurements reported here were carried out in Tübingen on a Bruker MSL 200 NMR spectrometer at 4.7 T and in Eindhoven on a Bruker CXP 300 NMR spectrometer at $7.05 \mathrm{~T}$ with samples of $200-300 \mathrm{mg}$ in double air bearing rotors of $\mathrm{Al}_{2} \mathrm{O}_{3}$ or $\mathrm{ZrO}_{2}$. Magic angle spinning was routinely carried out at $4-\mathrm{kHz}$ spinning rates. Typically, the proton $90^{\circ}$ pulse length was $6 \mu$ s and the repetition time $2 \mathrm{~s}$. For CP curves 1100 fid's for 16 different $\tau$-values between 0.1 and $40 \mathrm{~ms}$ were accumulated. To eliminate experimental artifacts, block 
TABLE I: $T_{1 \rho \mathrm{H}}{ }^{a}$ and $T_{\mathrm{HSI}}{ }^{a}$ Values for Silica Gels $\left(B_{0}=4.7 \mathrm{~T}\right)$

\begin{tabular}{|c|c|c|c|c|c|}
\hline silica gel & species & $T_{\mathrm{HSi}}$ & $T_{1 \rho \mathrm{H}}{ }^{b}$ & $T_{1 \rho \mathrm{H}^{c}}$ & $T_{1 \rho \mathrm{H}^{d}}$ \\
\hline \multirow{3}{*}{ Hypersil (5-192) } & $\mathrm{Q}^{3}$ & 0.1 & 17.2 & 22.4 & 19.2 \\
\hline & $\mathrm{Q}^{4}$ & 2.0 & 6.4 & 20 & 14.6 \\
\hline & & 16.8 & & 32.3 & \\
\hline \multirow[t]{3}{*}{ Nucleosil (5051) } & $Q^{2}$ & 0.8 & 11.4 & 12.2 & \\
\hline & $Q^{3}$ & 1.3 & 25.8 & 25 & 25.9 \\
\hline & $\mathrm{Q}^{4}$ & 5.7 & 26.4 & 28 & 27.7 \\
\hline \multirow[t]{3}{*}{ Nucleosil (4111) } & $\mathrm{Q}^{2}$ & 0.9 & 7.4 & 7.7 & \\
\hline & $\mathrm{Q}^{3}$ & 1.4 & 14.2 & 15.3 & 14.4 \\
\hline & $Q^{4}$ & 4.5 & 15.1 & 16.2 & 14.7 \\
\hline \multirow{4}{*}{ Nucleosil (5061) } & $\mathrm{Q}^{2}$ & 1.6 & 21.3 & 22 & 21.9 \\
\hline & $Q^{3}$ & 1.9 & 19.2 & 25 & 23.7 \\
\hline & $\mathrm{Q}^{4}$ & 1.7 & 13.6 & 24.7 & 19.1 \\
\hline & & 21.5 & & 46.9 & \\
\hline
\end{tabular}

${ }^{a}$ In milliseconds; the reproducibilities are ca. $5 \%$ for the siloxanes $Q^{4}$ and the silanols $Q^{3}$ and ca. $10 \%$ for the silanediols $Q^{2}$. ${ }^{b}$ Values obtained by the method described by Schaefer ${ }^{7,9}$ with a contact time of 4 ms. "Values obtained by the method described by Schaefer ${ }^{7,9}$ with a contact time of $8 \mathrm{~ms}$. ${ }^{d}$ Values obtained by the method described by Schaefer ${ }^{7,9}$ with a contact time of $16 \mathrm{~ms}$.

averaging was used to spread out over time the individual measurements. All ${ }^{29} \mathrm{Si}$ spectra were externally referenced to liquid tetramethylsilane $\left(\mathrm{Me}_{4} \mathrm{Si}\right)$ and the chemical shifts are given in parts per million.

The pulse sequences used have been described in detail elsewhere. ${ }^{7}$ The spin-lattice relaxation time $T_{1 \mathrm{Si}}$ was measured by a spin-temperature-alternated cross-polarization pulse sequence followed by $90^{\circ}$ phase shifted $\pi / 2-\tau-\pi / 2{ }^{29} \mathrm{Si}$ pulse sequence or by Bloch decay. The recycle delays are greater than 5 times $T_{1 \mathrm{H}}{ }^{8}$ or 5 times $T_{1 \mathrm{Si}}$ (Bloch decay). The reproducibilities of our $T_{1 \mathrm{Si}}$ measurements are ca. $5 \%$ for the large signals of $\mathrm{Q}^{4}$, ca. $10 \%$ for the silanol signals, and ca. $20 \%$ for the small silanediol signals.

The proton relaxation time $T_{1 \mathrm{H}}$ was measured indirectly by inversion recovery via detection of ${ }^{29} \mathrm{Si}$ resonances. ${ }^{7}$ The proton relaxation time in the rotating frame $T_{1 \rho \mathrm{H}}$ was measured as described by Schaefer and Stejskal. ${ }^{9}$ A relaxation period of length $\tau$ is inserted between the beginning of the ${ }^{1} \mathrm{H}$ spin-lock condition and the beginning of the contact period. By observation of the ${ }^{29} \mathrm{Si}$ intensity at the end of the contact period as a function of $\tau$, $T_{1 \rho \mathrm{H}}$ can be determined. $T_{\mathrm{HSi}}$ is determined by variation of the contact time?

$\mathrm{Q}^{2} / \mathrm{Q}^{3}$ ratios near the surfaces were obtained by $\mathrm{CP}$ excitation for Nucleosil batch 4111 (contact time $5 \mathrm{~ms}$ ), Nucleosil batch 5051 (contact time $5 \mathrm{~ms}$ ), and Nucleosil batch 5061 (contact times 5 and $8 \mathrm{~ms}$ ). Peak intensities were corrected by using the formula ${ }^{9 b}$

$$
I_{t}=\frac{I_{0}}{T_{\mathrm{HSi}}}\left[\frac{e^{-t / T_{1 \rho \mathrm{H}}}-e^{-t / T_{\mathrm{HSi}}}}{\frac{1}{T_{\mathrm{HSi}}}-\frac{1}{T_{1 \rho \mathrm{H}}}}\right]
$$

Peak deconvolution was applied where necessary, using the standard Bruker LINESIM procedure.

\section{Results}

A. Cross-Polarization Characteristics, a. Basis Silica Gels. It has been reported previously that ${ }^{29} \mathrm{Si}$ CP MAS NMR provides valuable information about the different surface species of silica. In our efforts to get more insight in the mechanism of the chromatographic process, ${ }^{2 d, e}$ we were interested in the surface characterization of different types of silica. The dynamic properties of silica surface species are revealed by relaxation parameters in the laboratory and the rotating frame, such as $T_{1 \mathrm{H}}, T_{1 \mathrm{Si}}, T_{\mathrm{HSi}}$, and $T_{1 \rho \mathrm{H}}$.

A typical ${ }^{29} \mathrm{Si}$ CP MAS NMR spectrum of a silica gel shows three signals: geminal groups $Q^{2}$, silanol groups $Q^{3}$, and siloxane

(7) Sullivan, M. J.; Maciel, G. E. Anal. Chem. 1982, 54, 1615

(8) Torchia, D. A. J. Magn. Reson. 1978, 30,613.

(9) (a) Schaefer, J.; Stejskal, E. O.; Buchdahl, R. Macromolecules 1977, 10,384. (b) Garroway, A. N.; Moniz. W. B.; Resing, H. A. ACS Symp. Ser. $1979,103,67$

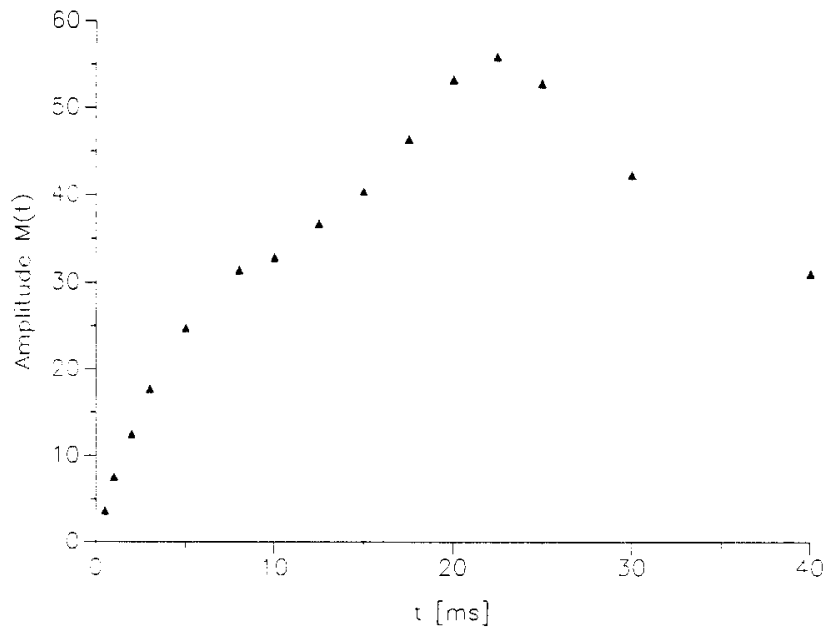

Figure 1. Plot of ${ }^{29} \mathrm{Si} C P$ NMR magnetization of the siloxane unit $\mathrm{Q}^{4}$ of Nucleosil (Batch 5061).

TABLE II: $Q^{2} / Q^{3 a}$ Ratio for Silica Gels

\begin{tabular}{cccc}
\hline silica gel & $\mathrm{Q}^{2} / \mathrm{Q}^{3 b}$ & $\mathrm{Q}^{2} / \mathrm{Q}^{3 c}$ & $\mathrm{Q}^{2} / \mathrm{Q}^{3 d}$ \\
\hline Nucleosil $(5051)$ & $1 / 5.3$ & $1 / 5.4$ & $1 / 5.3$ \\
Nucleosil $(4111)$ & $1 / 5.5$ & $1 / 5.6$ & $1 / 5.5$ \\
Nucleosil $(5061)$ & $1 / 5.2$ & $1 / 4.9$ & $1 / 5.0$
\end{tabular}

${ }^{a}$ Determined according to formula 1 with the contact time $t$ of $5 \mathrm{~ms}$ and the $T_{1 \rho \mathrm{H}}$ and $T_{\mathrm{HSi}}$ values noted in Table I. ${ }^{b} T_{l_{\rho \mathrm{H}}}$ values obtained by the method described by Schaefer ${ }^{7,9}$ with a contact time of $4 \mathrm{~ms}$. ${ }^{\circ} T_{l_{\rho \mathrm{H}}}$ values obtained by the method described by Schaefer ${ }^{7,9}$ with a contact time of $8 \mathrm{~ms}$. ${ }^{d} T_{1 \rho \mathrm{H}}$ values obtained by the method described by Schaefer ${ }^{7,9}$ with a contact time of $16 \mathrm{~ms}$.

groups $\mathrm{Q}^{4}$ are indicated by signals at $-91 \mathrm{ppm},-100 \mathrm{ppm}$, and $-109 \mathrm{ppm}$, respectively. ${ }^{1}$ The dependence of the amplitudes of each of the three ${ }^{29} \mathrm{Si}$ NMR signals on the contact (or cross polarization) time is governed by formula 1 (see Experimental Section). The $T_{\mathrm{HSi}}$ and $T_{1 \rho \mathrm{H}}$ values for the three signals were determined by using standard Bruker software (SIMFIT); for results see Table I. The CP curves pass through a maximum value. Maximal signal to noise ratios will be obtained for that particular signal when the contact time is chosen according to the contact time belonging to the maximum in the $\mathrm{CP}$ curve. Obviously, the "optimum contact time" depends on both $T_{\mathrm{HSi}}$ and $T_{1 \rho \mathrm{H}}$. In most cases, $T_{1 \rho \mathrm{H}}$ turns out to be considerably larger than $T_{\mathrm{HSi}}$ and in those cases, the optimum contact times are determined largely by the $T_{\mathrm{HSi}}$ values.

Typical "maxima" in the CP curves of $Q^{3}$ and $Q^{4}$ groups for most silica gels (details not given here) range between 6 and 8 $\mathrm{ms}$ and from 8 to ca. $20 \mathrm{~ms}$, respectively. For Hypersil 5-192 the $\mathrm{CP}$ curve for the $\mathrm{Q}^{3}$ signal shows a "maximum" near $2-3 \mathrm{~ms}$, signifying significantly shorter $T_{\mathrm{HSj}}$ values than for any of the other silica gels studied here.

In most silica gels the siloxane groups $\mathrm{Q}^{4}$ show similar shapes of $\mathrm{CP}$ curves ${ }^{1}$ and thus similar $T_{\mathrm{HSi}}(4.5-6.5 \mathrm{~ms})$ and $T_{1 \rho \mathrm{H}}$ values (16-26 ms). As an example, the values of Nucleosil (batch 4111, batch 5051) are presented in Table I. There are only slight differences in the $T_{1 \rho \mathrm{H}}$ values determined by an experiment described by Schaefer et al., ${ }^{11}$ using different contact times (Table I). In contrast, for batch 5061, in addition to the broad maximum at $22.5 \mathrm{~ms}$ a second maximum at $8 \mathrm{~ms}$ is found (Figure 1). Here two different $T_{\mathrm{HSi}}$ values of 1.7 and $21.5 \mathrm{~ms}$ can be determined (Figure 2a) as well as two different $T_{1 \rho \mathrm{H}}$ values of 24.7 and 46.9 ms (Figure 2b). A similar situation prevails for Hypersil 5-192 silica gel. In these silicas, there is a strong dependence of the

(10) (a) Watanabe, T.; Shimizu, H.; Masuda, A.; Saitô, H. Chem. Lett. 1983, 1293. (b) Barron, P.; Slade, P.; Frost, R. L. J. Phys. Chem. 1985, 89 , 3305. (c) Iwamiya, J. H.; Gerstein, B. C. Zeolites 1986, 6, 181. (d) van de Ven, L. J. M.; Post, J. G.; van Hooff, J. H. C.; de Haan, J. W. J. Chem. Soc., Chem. Commun. 1985, 214.

(11) Barron, P. F.; Frost, R. L.; Skjemstad, J. O. J. Chem. Soc., Chem. Commun. 1983, 581 . 


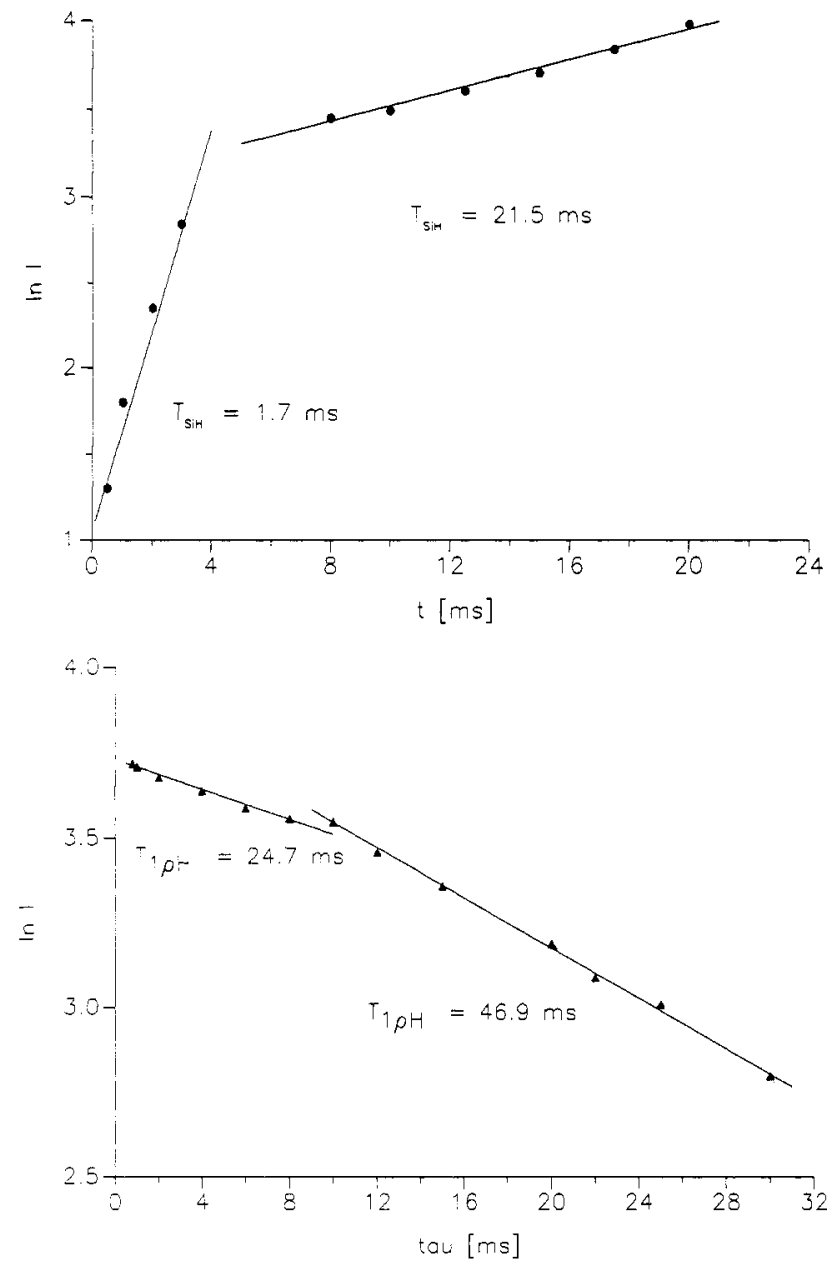

Figure 2. (a, top) Development of the ${ }^{29} \mathrm{Si}$ magnetization of the siloxane units $\mathrm{Q}^{4}$ of Nucleosil (batch 5061) characterized by the time constant for maximum ${ }^{29} \mathrm{Si}$ magnetization $T_{\mathrm{HS}}$. (b, bottom) Decay of the ${ }^{29} \mathrm{Si}$ magnetization of the siloxane units $\mathrm{Q}^{4}$ of Nucleosil (batch 5061) characterized by the relaxation time in the rotating frame $T_{1 \rho \mathrm{H}}$.

TABLE III: $Q^{2} / Q^{3} / Q^{4 a}$ Ratio for Silica Gels

\begin{tabular}{ccc}
\hline silica gel & $\mathrm{Q}^{2} / \mathrm{Q}^{3} / \mathrm{Q}^{4 b, d}$ & $\mathrm{Q}^{2} / \mathrm{Q}^{3} / \mathrm{Q}^{4 c}$ \\
\hline Nucleosil (5051) & $8.4 / 46.8 / 44.8$ & $8.6 / 46.8 / 44.6$ \\
Nucleosil (4111) & $9.3 / 51.8 / 38.8$ & $9.3 / 51.8 / 38.8$
\end{tabular}

a Determined according to formula 1 with the contact time $t$ of $5 \mathrm{~ms}$ and the $T_{1 \rho \mathrm{H}}$ and $T_{\mathrm{HSi}}$ values noted in Table $1 .{ }^{b} T_{1 \rho \mathrm{H}}$ values obtained by the method described by Schaefer, 7,9 with a contact time of $4 \mathrm{~ms}$. $c T_{1 \rho \mathrm{H}}$ values obtained by the method described by Schaefer ${ }^{7,9}$ with a contact time of $8 \mathrm{~ms}$. ${ }^{d} T_{1 \mathrm{pH}}$ values obtained by the method described by Schaefer 7.9 with a contact time of $16 \mathrm{~ms}$.

siloxane $T_{1 \rho \mathrm{H}}$ values obtained upon the chosen contact time. $T_{1 \rho \mathrm{H}}$ measurements at short contact times $(4 \mathrm{~ms})$ result in relatively low $T_{1 \rho \mathrm{H}}$ values and at long contact times $(16 \mathrm{~ms})$ in higher values. Two $T_{1 \rho \mathrm{H}}$ values are obtained with a contact time of $8 \mathrm{~ms}$ (Table 1). See also below.

A similar behavior is found for Cab-O-Sil, a fumed silica without pores. In Table I the relaxation parameters are summarized for all silicas studied here.

The batch-to-batch variations of Nucleosil described above are hardly reflected in the silanediol/silanol ratio $Q^{2} / Q^{3}$, as seen in Table II. Silica gels with homogeneous surfaces show only slight differences in the $Q^{2} / Q^{3} / Q^{4}$ ratios calculated by using formula 1 with $T_{1 \rho \mathrm{H}}$ values obtained at different contact times (Table III) Even in heterogeneous materials the $\mathrm{Q}^{2} / \mathrm{Q}^{3}$ ratio is not strongly dependent upon the $T_{1 \rho \mathrm{H}}$ values (determined with different contact times). The $\mathrm{Q}^{2} / \mathrm{Q}^{3} / \mathrm{Q}^{4}$ ratios of heterogeneous surfaces could not be estimated, because it was not possible to calculate the "real" intensity $I_{0}$ of the siloxanes, since here at least two different $T_{\mathrm{HS}}$ and different $T_{1 \rho \mathrm{H}}$ values exist (depending on the chosen contact
TABLE IV: $T_{1}{ }^{a}$ Values for Silica Gels $\left(B_{0}=7.05 \mathrm{~T}\right)$

\begin{tabular}{lccc}
\hline & method & $\mathrm{Q}^{3}$ & $\mathrm{Q}^{4}$ \\
\hline Alpha Products-60 & $\mathrm{IR}^{b}$ & 21.5 & 24.8 \\
Alpha Products-60 & $\mathrm{CP}^{c}$ & 24.4 & 41.5 \\
Nucleosil (4111) & $\mathrm{IR}^{b}$ & 31.6 & 41.9 \\
Nucleosil (5061) & $\mathrm{CP}^{c}$ & 24.5 & 44.0 \\
Lichrosorb SI-60 & $\mathrm{IR}^{b}$ & 36.3 & 41.6 \\
Zorbax & $\mathrm{IR}^{b}$ & 33.3 & 44.4 \\
Hypersil (5-192) & $\mathrm{IR}^{b}$ & 31.6 & 41.9
\end{tabular}

${ }^{a}$ In seconds. ${ }^{b}$ Measured by the inversion recovery method with ${ }^{\prime} \mathrm{H}$ decoupling during acquisition; no differences for silica gels vacuumdried at $100{ }^{\circ} \mathrm{C}$. ${ }^{\circ}$ Cross polarization excitation according to Torchia, ${ }^{8}$ contact time $5 \mathrm{~ms}$.

TABLE V: $T_{1}{ }^{a}$ Values for Monofunctional Derivatized Nucleosil Batch $4111\left(B_{0}=7.05 T\right)$

\begin{tabular}{cccc}
\hline $\begin{array}{c}\text { carbon } \\
\text { load, \% }\end{array}$ & silane & $\mathrm{Q}^{3}$ & $\mathrm{Q}^{4}$ \\
\hline 0 & & $31.6(0.5)$ & $41.9(0.5)$ \\
7.3 & $10.0(2.0)$ & $35.1(3.1)$ & $49.9(1.7)$ \\
16.3 & $14.8(2.7)$ & $32.2(2.8)$ & $44.0(2.9)$
\end{tabular}

${ }^{a}$ In seconds, measured by the inversion recovery method with ${ }^{1} \mathrm{H}$ decoupling during acquisition; figures in parentheses are maximum deviations.

time). At this moment we are not able to estimate exactly the weighted amount of the siloxanes with low and high $T_{\mathrm{HSi}}$ and $T_{1 \rho \mathrm{H}}$ values, which would be necessary for quantification. Therefore, with CP excitation it makes only sense to determine the $Q^{2} / Q^{3}$ ratios in these materials.

b. Monofunctionally Derivatized Silica Gels. The silane signal (ca. $+12 \mathrm{ppm}$ ) itself shows relatively large variations in cross polarization behavior. The variations follow more or less those already existing for the $\mathrm{Q}^{4}$ and/or $\mathrm{Q}^{3}$ signals of the respective parent silicas. For example, the silane ${ }^{29} \mathrm{Si}$ CP MAS NMR signal of monofunctionally (octadecyl) derivatized Hypersil has a rather small $T_{\mathrm{HSi}}$ value, reflected in an "optimal contact time" near 5 $\mathrm{ms}$. This latter value should be compared with ca. $15 \mathrm{~ms}$ for the signal of the correspondingly modified Nucleosil, the $T_{1 \rho \mathrm{H}}$ values being quite close. These differences probably reflect different silane mobilities at different silica supports, but could also in part be due to cross effects between silanes and remaining silanols. Further explanations should await a systematic study at different silicas for different degrees of silylation.

B. $T_{1 \mathrm{Si}}$ Values. Measurements of $T_{1 \mathrm{Si}}$ values have been presented by Fyfe et al. for native and for monofunctionally derivatized Fisher S-157 silica. Values for $T_{1}$ were reported for silanediol, silanol, siloxy, and silane silicons. ${ }^{6}{ }^{29} \mathrm{Si}$ NMR $T_{1}$ values of quite different magnitudes have been reported for a number of compounds ${ }^{10}$ including extremely large $T_{1 \mathrm{Si}}$ values. ${ }^{11}$ Some of these $T_{1 \mathrm{Si}}$ values were obtained by using CP excitation while other measurements, including those of Fyfe, implied pulse excitation. ${ }^{6}$ Although no numbers of scans are mentioned by Fyfe et al., their results appear to indicate that quantitatively useful ${ }^{29}$ Si MAS NMR spectra can be obtained for native silica gels by using pulse interval times of $\mathrm{ca} .100 \mathrm{~s}$ and for monofunctionally derivatized gels with interval times of ca. $200 \mathrm{~s}$.

$i$. With Pulse Excitation. Our $T_{1 \mathrm{Si}}$ values for five different silica gels, as summarized in Table IV, indicate considerably larger values than those of Fyfe. ${ }^{6}$ Monoexponential analysis (see also section $\mathrm{C}$ ) result in $T_{1 \mathrm{Si}}$ values ranging from $\mathrm{ca} .21 \mathrm{~s}$ to $\mathrm{ca} .36$ $\mathrm{s}$ for $\mathrm{Q}^{3}$ and from ca. $25 \mathrm{~s}$ to $\mathrm{ca} .44 \mathrm{~s}$ for $\mathrm{Q}^{4}$. This may very well be caused by the lower $\mathrm{Q}^{2}$ and $\mathrm{Q}^{3}$ contents of our silica gels: typically ca. $1 \%$ and $24 \%$, respectively, of the total signal area as measured with Bloch pulse excitation and sufficiently long pulse delays. Fyfe et al. ${ }^{6}$ report percentages of 6.5 and ca. 37 for $\mathrm{Q}^{2}$ and $\mathrm{Q}^{3}$, respectively. Table $\mathrm{V}$ contains our results at $7.05 \mathrm{~T}$ for monofunctionally octadecyl-derivatized Nucleosil (batch 4111)

(12) Hockey, J. A.; Pethrica, B. A. Trans. Faraday Soc. 1961, 57, 2247

(13) Pfleiderer, B.; Albert, K.; Bayer, E. To be published. 
with ca. $7 \% \mathrm{C}$ (total carbon content as detected by elemental analysis) and with ca. $16 \% \mathrm{C}$. Apart from the silane ${ }^{29} \mathrm{Si} \mathrm{NMR}$ signal at $+12 \mathrm{ppm}$, the differences in $T_{1 \mathrm{Si}}$ values are relatively small. $T_{1 \mathrm{Si}}$ values for the native silica gel are also included.

ii. With CP Excitation. Cross polarization excitation is in principle a selective excitation method, in contrast to Bloch pulse excitation with a sufficiently long pulse interval. Silica gels have different degrees of inhomogeneities. Quaternary silicon atoms, for instance, can be subdivided into those having one or two silanol silicons as next neighbors and those having only other quaternary silicons in the first "coordination sphere". It might therefore be expected that different $T_{1}$ values will be found for different cross-polarization times. This was, however, not borne out by our experimental results: the same value of $T_{1 \mathrm{Si}}$ was found for contact times ranging from 0.5 to $8 \mathrm{~ms}$ for, e.g., Alfa Products silica and for Nucleosil batch 4111. For clearly inhomogeneous materials, such as Nucleosil batch 5061 (see before), different $T_{1 \mathrm{Si}}$ values are found for different contact times, resembling the results of the $T_{1 \rho \mathrm{H}}$ measurements. The $T_{\mathrm{ISi}}$ values for Nucleosil (batch 5061 ), obtained at a contact time of $5 \mathrm{~ms}$, are for $\mathrm{Q}^{2}, \mathrm{Q}^{3}$, and $\mathrm{Q}^{4}$ units $29 \pm 2.3,29.4 \pm 1.8$, and $43.4 \pm 4.7 \mathrm{~s}$, respectively. Measurements at a contact time of $16 \mathrm{~ms}$ result for $\mathrm{Q}^{2}, \mathrm{Q}^{3}$, and $\mathrm{Q}^{4}$ in $33 \pm 2.8,43.4 \pm 2.15$, and $53 \pm 5.2 \mathrm{~s}$, respectively. Table IV allows a comparison of the results of single exponential $T_{1}$ 's obtained on silica gel at a contact time of $5 \mathrm{~ms}$ with $\mathrm{CP}$ and results for Bloch pulse excitation. There are only slight differences in the results for the silanol groups, whereas great differences are found for the siloxanes. The values determined with CP are generally higher. This is evidence that the heterogeneity of the silica gel is mainly due to the siloxanes.

C. Multiexponential Analysis of Relaxation Rates. Longitudinal relaxation of ${ }^{29} \mathrm{Si}$ NMR signals of silica gels is generally a multiexponential process, dictated by the nature of the samples (see above). Analyses of relaxation rates in terms of a singleexponential function is, therefore, a simplification. This becomes evident, e.g., when plotting signal amplitudes versus pulse interval times in a $\log$ plot as presented in ref 6 . On the other hand, a separation of relaxation rates of ${ }^{29} \mathrm{Si}$ NMR signals of silica gels into several distinct contributions will be elusive because there will be a very broad range of time constants involved in the overall relaxation rate. In practice, analyses in terms of many time constants will be limited by the number of measurements, e.g., different $\pi-\pi / 2$ pulse interval times.

In the present study, we choose to analyze the longitudinal relaxation of the ${ }^{29} \mathrm{Si}$ NMR signal of the Alpha Products silica gel under one set of conditions (dried silica gel, measured in laboratory air, Bloch decay) in terms of three relaxation rates according to the formula

$S(t)=$

$$
a(1)\left[1-e^{-t / T_{1}(1)}\right]+a(2)\left[1-e^{-t / T_{1}(2)}\right]+a(3)\left[1-e^{-t / T_{1}(3)}\right]
$$

in which $S(t)$ is the total signal as a function of pulse interval time $t, T_{1}(1)-T_{1}(3)$ are three different relaxation times, and $a(1)-a(3)$ are the respective preexponential factors. For practical reasons (available number of measurements) we are restricted to a three-exponential analysis of the present results. The three different relaxation times represent in fact average values for three different ranges. For the ${ }^{29} \mathrm{Si}$ NMR signal of the quaternary silicon atoms near $-110 \mathrm{ppm}$, this results in

$S(t)=0.40\left(1-e^{-t / 67}\right)+0.34\left(1-e^{-t / 19}\right)+0.26\left(1-e^{-t / 2}\right)$

This is to be compared with the "standard analysis" in terms of three constants as in (9)

$$
S(t)=a_{1}+a_{2}\left(1-e^{\left.-t / T_{\mathrm{ISi}}\right)}\right.
$$

$a_{1}$ and $a_{2}$ being constants; eq 4 yields $T_{1 \mathrm{Si}}=26.6 \mathrm{~s}$ for this particular measurement. The division into three new average $T_{1}$ values may perhaps be rationalized as follows. The values of ca. $67 \mathrm{~s}$ and ca. $19 \mathrm{~s}$ correspond with quaternary silicons having none and one silanol as a nearest neighbor, respectively. The latter value may very well represent an average for ${ }^{29} \mathrm{Si}$ nuclei interacting with mobile and those interacting with more rigid silanol protons. The fast relaxing quaternary silicons may be close to paramagnetic centers. ${ }^{10 a, b}$ As suggested by Klinowski, ${ }^{14}$ paramagnetic oxygen also contributes measurably. Longitudinal relaxation of the ${ }^{29} \mathrm{Si}$ NMR signal assigned to the silanol groups near -101 ppm (same sample as above) proceeds according to

$$
S(t)=0.34\left(1-e^{-t / 81}\right)+0.43\left(1-e^{-t / 12}\right)+0.23\left(1-e^{-t / 0.2}\right)
$$

to be compared with the "averaged value" (single-exponential analysis) of $T_{1}=19.7 \mathrm{~s}$. The most remarkable result of this calculation seems to be the presence of a significant contribution of rather slowly relaxing ${ }^{29} \mathrm{SiOH}$ nuclei $\left(T_{1} \approx 81 \mathrm{~s}\right)$. Its relative contribution is comparable to that of the slowly relaxing quaternary silicon signals. The magnitudes of the $T_{1}$ values of silanol groups and quaternary silicons are of the same order. This seems feasible, assuming very small dipolar contribution of silanol protons to the relaxation rates of either type of silicon nucleus, plus the existence of domains with different mobilities.

\section{Discussion}

i. Quantification. As already mentioned in the Introduction, pulse excitation has been put forward as an attractive method for obtaining quantitatively dependable ${ }^{29} \mathrm{Si}$ MAS NMR spectra of silica gels. ${ }^{6}$ In practice, however, typical $T_{1 \mathrm{Si}}$ values range from 25 to $50 \mathrm{~s}$; see also Results. For a series of dependable, quantitative NMR measurements, these $T_{1 \mathrm{Si}}$ values should be measured in advance since there is a rather large spread in the values. Such a measurement takes typically at least $60 \mathrm{~h}$ of instrument time after which a spectrum can be obtained overnight, assuming the largest $T_{1 \mathrm{Si}}$ value is ca. $40 \mathrm{~s}$. Without adequate $T_{1 \mathrm{Si}}$ measurements for at least one sample of a series of silica gels, one would have to anticipate $T_{1 \mathrm{Si}}$ values of perhaps $100 \mathrm{~s}$, requiring pulse delay times of $600 \mathrm{~s}$. In practice, ca. 500 scans are needed for a useful signal to noise ratio, amounting to measurement times of the order of $80 \mathrm{~h}$.

With cross polarization, a typical spectrum can be obtained in ca. $1 \mathrm{~h}$. Here, too, calibration measurements are necessary. The present results indicate that $\mathrm{CP}$ curves should be measured at least for one typical member of a series of basis silica gels (ca. $15 \mathrm{~h}$ measurement time) since the variation in $\mathrm{CP}$ behavior between different silica gels is considerable. A similar situation prevails for monofunctionally derivatized materials. It will be shown elsewhere ${ }^{13}$ that no separate $C P$ curves are needed for biand trifunctionally silylated silica gels since in these cases the optimum contact times are independent of the basis silica gel, both for the silanol groups and for the silane signals. In view of the results already in the literature and those presented in the present paper, our conclusion is that $C P$ excitation is always to be recommended for ${ }^{29} \mathrm{Si}$ MAS NMR of silica gels except in those cases where dependable relative intensities, also including bulk $\left(\mathrm{Q}^{4}\right)^{29} \mathrm{Si}$, are required for structural analyses.

In addition, it will be shown in the next paragraphs that the form of the CP curves, especially for basis silica gels, yields additional information, regarding regions of different mobilities in the sample. This information can probably be related to the non-single-exponential behavior of ${ }^{29} \mathrm{Si}$ longitudinal relaxation.

ii. Cross-Polarization Characteristics. In our view, the spin dynamics of ${ }^{29} \mathrm{Si}$ and ${ }^{1} \mathrm{H}$ nuclei of silica gels should be described in terms of two different proton spin assemblies. One, comprised of the silanediol protons, is coupled to the appropriate silanediol silicon atoms. The other, comprised of the silanol protons, is coupled to the silanol silicon atoms. Both types of protons will yield a contribution to the cross polarization of quaternary silicon nuclei. In contrast to Maciel, ${ }^{1}$ we prefer the explanation that the $T_{1 \rho \mathrm{H}}$ values of silanediols and those of silanols differ and that

(14) Klinowski, J.; Carpenter, T. A.; Thomas, J. M. J. Chem. Soc., Chem. Commun. 1986, 956 .

(15) de Haan, J. W; van den Bogaert, H. M.; Ponjeë, J. J.; van de Ven L. J. M. J. Colloid Interface Sci. 1986, 110, 591.

(16) van de Ven, L. J. M.; de Haan, J. W. To be published. 
siloxane silicon nuclei will experience a weighted average of 2 . From the last parts of the CP curves (longer contact times), it becomes clear that different values for $T_{1 \rho \mathrm{H}}$ are found for $\mathrm{Q}^{3}$ (silanol) and $\mathrm{Q}^{2}$ (silanediol) protons. Therefore, we assume that there is no fast spin diffusion between the silanol protons on one side and silanediol groups on the other side. There is, however, no way of knowing that all silanol protons have exactly the same $T_{10 \mathrm{H}}$; the same is true for silanediol protons. The magnetization decays in the $\mathrm{CP}$ curves show approximately single-exponential behavior. The dynamics can then be expressed by a formula of the type

$$
\frac{1}{T_{1 \rho \mathrm{H}}\left(\mathrm{Q}^{4}\right)}=\left[\frac{B}{T_{1 \rho \mathrm{H}}\left(\mathrm{Q}^{3}\right)}+\frac{C}{T_{1 \rho \mathrm{H}}\left(\mathrm{Q}^{2}\right)}\right] A
$$

In formula $6 B$ and $C$ denote the relative amounts of silanol $\left(Q^{3}\right)$ and silanediol $\left(\mathrm{Q}^{2}\right)$ sites, respectively, while $A$ stands for the interaction efficiency between $\mathrm{Q}^{4}$ silicons and protons. This latter interaction is decreased, caused by the larger internuclear distances. CP curves with more than one maximum were observed for a number of silica gels, especially for $\mathrm{Q}^{4}$ signals, independently at two different field strengths (4.7 and 7.05 T). In our view, this has to be ascribed to (surface) regions with different cross-polarization behaviors, characterized by different $T_{\mathrm{HSi}}$ and $T_{1 \rho \mathrm{H}}$ values. In this description, the experimental $\mathrm{CP}$ curves for siloxane silicons, and possibly also for silanol and silanediol silicons, should be considered as composites of two or three different $\mathrm{CP}$ curves, each with characteristic values for $T_{\mathrm{HSi}}$ and $T_{1 \rho \mathrm{H}}$.

A preliminary analysis of the $\mathrm{CP}$ curve of the sample shown in Figure $1 \mathrm{~b}$ delivered two sets of time constants: $T_{\mathrm{HSi}}=1-2 \mathrm{~ms}$ and $T_{1 \rho \mathrm{H}} \approx 20-25 \mathrm{~ms}$ and $T_{\mathrm{HSi}}=\mathrm{ca} .30 \mathrm{~ms}$ and $T_{1 \rho \mathrm{H}}=\mathrm{ca} .50$ $\mathrm{ms}$, respectively.

$T_{\mathrm{HX}}\left(\mathrm{X}={ }^{29} \mathrm{Si},{ }^{13} \mathrm{C}\right.$, etc.) values are known to be related to mobilities of the molecular system under study in the $10^{2}-\mathrm{Hz}$ range. Likewise, $T_{1 \rho \mathrm{H}}$ values are sensitive to molecular motions around $10^{4}-10^{5} \mathrm{~Hz}$. The observed different contributions to the "overall CP curve" in this study thus signify a considerable spread in mobilities in the $10^{2}-10^{5}-\mathrm{Hz}$ range in the silicas under study. On the basis of these results, we conclude that there exist two regions consisting of (poly)crystalline $\beta$-tridymite characterized by $T_{\mathrm{HSi}}$ values of 1-2 ms and $T_{10 \mathrm{H}}$ values of $22-25 \mathrm{~ms}$ and those comprised of amorphous silica characterized by $T_{\mathrm{HSi}}$ values of $20-38 \mathrm{~ms}$ and $T_{1 \rho \mathrm{H}}$ values of $40-50 \mathrm{~ms}$.

The flexibly bound silicon atoms of the amorphous region require more time for polarization than the more rigidly bound silicons of the crystalline region and so the $T_{\mathrm{HSi}}$ and $T_{1 \rho \mathrm{H}}$ times are longer. The interpretations of our $\mathrm{CP}$ curves are based on the surface model of Hockey et al., ${ }^{12}$ which describes that for amorphous silicas in the glasslike state the essentially crystalline form of $\mathrm{SiO}_{4}$ tetrahedrons is still retained and that they closely resemble the arrangement present in $\beta$-cristobalite or $\beta$-tridymite. Consequently, the surface could consist of small crystalline domains in an amorphous surrounding. Similar suggestions have recently been made based on a model study of silasesquioxanes ${ }^{17}$ and were, implicitly, also made by Sindorf and Maciel. ${ }^{3 \mathrm{c}}$ An additional effect of pores can be excluded because the CP curve of Cab-O-Sil, a fumed silica without pores, shows also two contact time maxima for $\mathrm{Q}^{4}$ units.

Measurements of $\mathrm{CP}$ curves of Nucleosil after acid treatment ${ }^{19,20}$ revealed the same CP characteristics as observed for Nucleosil 5061 and Hypersil 5-162. Electron diffraction experiments of the treated Nucleosil, but not of the untreated one, show the reflections which are expected for (poly)crystalline $\beta$-tridymite. ${ }^{20}$ Moreover, the fact that the silanols in contrast to the

(17) Feher, F. J.; Newman, D. A.; Walzer, J. F. J. Am. Chem. Soc, 1989, 111,1741

(18) Hetem, M.; Rutten, G.; Vermeer, B.; Rijks, J.; van de Ven, L.; de Haan, J.; Cramers, C. J. Chromatog. 1989, $477,3$.

(19) (a) Pfleiderer, B.; Albert, K.; Bayer, E. Unpublished results. (b) Pfleiderer, B. Diplome Thesis, Tübingen University, Tübingen, FRG, 1986. 1988 . siloxanes hardly show that phenomenon (Table I) supports the model of Hockey. ${ }^{12}$

A more detailed description could be as follows. Normal silica gels are far from homogeneous materials. In some parts, local geometrics may resemble very much those of crystalline materials such as $\beta$-tridymite and/or $\beta$-cristoballite. Other parts are less ordered and are considered amorphous. The different parts are intermingled and therefore the "mechanical coupling" between the parts is rather strong. This makes it rather difficult for $\mathrm{CP}$ ${ }^{29} \mathrm{Si}$ MAS NMR experiments to distinguish between the two: averaged results of $T_{\mathrm{HS}}$ and $T_{1 \rho \mathrm{H}}$ will generally be measured. The numerical values of $T_{\mathrm{HSi}}$ and $T_{1 \rho \mathrm{H}}$ may of course depend on the relative contributions of ordered and amorphous regions. This can very well explain the existence of differences between different brands of silica and of batch-to-batch differences within a given brand. Upon acid treatment as described by Lork, ${ }^{20}$ the amorphous parts are more readily dissolved ("leaching"). The result is a rigid core of (poly)crystalline material from which chains of silicate ("fractals") protrude. The mechanical coupling between the two types of material disappears to a large extent and the $C P$ curves show the separate contributions of the hard cores (small $T_{\mathrm{HSi}}$ and $T_{\mathrm{l} \rho \mathrm{H}}$ values) and of the fractal chains. The latter then consist of the sum of contributions of silicon nuclei of quite different mobilities. This cannot easily be described by a single CP curve with only one $T_{\mathrm{HSi}}$ and $T_{1 \rho \mathrm{H}}$ value. The curve is very reminiscent of those found for polysiloxane chains, immobilized on the silica surface. ${ }^{18}$ Similar $\mathrm{CP}$ curves can be measured for $\mathrm{CH}_{2}$ groups in an octyl or octadecyl chain, anchored on a surface. ${ }^{18}$ After silylation with monofunctional organosilanes the remaining silanol ${ }^{29} \mathrm{Si}$ CP MAS NMR signal exhibits essentially the same "optimum contact time" as the basis silica. This result signifies that the overall mobilities of the surface species $\left(Q^{2}, Q^{3}, Q^{4}\right.$ units $)$ do not change significantly upon monofunctional substitution.

Differences in CP characteristics of the silane signals probably reflect different silane mobilities at different silica supports but could also in part be due to cross effects between silanes and remaining silanols. Further explanations should await a systematic study at different silicas for different degrees of silylation.

For bi- and trifunctionally derivatized materials, the situation is completely different from monofunctionally derivatized materials. The CP characteristics of the silane silicon now depend almost exclusively on the immediate surroundings of the silicon: bi- or trifunctional. Therefore, the results are practically independent of the silica support. Polyfunctional silanes can form cross links which increase the rigidity of the surface structures and also equalize the different mobilities. ${ }^{13}$

iii. $T_{1}$ Values. In combination with our $\mathrm{CP}$ curves of silica gels, we propose the following explanation. After cross polarization only those ${ }^{29} \mathrm{Si}$ atoms having the more efficient dipolar interactions with protons will be excited. These components of the total ${ }^{29} \mathrm{Si}$ CP NMR spectrum turn out to have a considerably more efficient longitudinal relaxation than average. This becomes evident in two ways. Firstly, we carried out $\mathrm{CP}$ inversion recovery experiments without proton spin temperature alternation and with coherent addition (i.e., one half of the Torchia experiment ${ }^{8}$ ). After a waiting period of 5-10 s only "positive" ${ }^{29} \mathrm{Si} \mathrm{NMR}$ signals were observed, signals becoming larger with longer waiting times. Secondly, including short waiting times in the proper CP $T_{1}$ experiments, ${ }^{8}$ we consistently observed an "oscillatory" dependence of the ${ }^{29} \mathrm{Si}$ NMR signal on the waiting period (a typical list of waiting times included 10 values spread out over $0.01-1.5 \mathrm{~s}$ ). The above-mentioned dependences of ${ }^{29} \mathrm{Si}$ NMR signals on waiting periods can only be explained by invoking very fast $\left(T_{1} \sim 0.1-0.3\right.$ $\mathrm{ms}$ ) relaxation of a large part of the original ${ }^{29} \mathrm{Si}$ CP NMR signals, accompanied by much slower $\left(T_{1}^{\prime} \sim 20-40 \mathrm{~s}\right)$ relaxation of the other ${ }^{29} \mathrm{Si}$ NMR signals plus a rather efficient interaction (exchange) between the two types of nuclei $(T \leq 1 \mathrm{~s}) .{ }^{16}$ The derivation of the dependence of the ${ }^{29} \mathrm{Si}$ NMR signal on the time is as follows

$$
S_{t}=S_{0} e^{-z / T_{1}}
$$

in which $T_{1}$ is the longitudinal relaxation time $T_{1 \mathrm{Si}}$. When 
TABLE VI: $T_{1}, T_{1}^{\prime}$, and $T_{d}$ Values $^{a}$ Obtained by Simulation According to Formula 10 of $T_{1 S t}$ Measurements ${ }^{8}$ with Short Waiting Periods

\begin{tabular}{ccccc}
\hline & & $T_{1}$ & $T_{1}^{\prime}$ & $T_{\mathrm{d}}$ \\
\hline Alpha Products & $\mathrm{Q}^{3}$ & 0.22 & 24.4 & 0.75 \\
& $\mathrm{Q}^{4}$ & 0.23 & 41.5 & 0.93 \\
Nucleosil (5061) & $\mathrm{Q}^{3}$ & 0.11 & 24.5 & 0.53 \\
& $\mathrm{Q}^{4}$ & 0.12 & 44.0 & 0.62 \\
a In seconds. & & & &
\end{tabular}

magnetization is exchanged with other nuclei (longitudinal relaxation time $T_{1}{ }^{\prime}$ ) with a time constant $T_{\mathrm{d}}$, eq 7 transforms to eq 8:

$$
S_{t}=S_{0} e^{-t / T_{1}} e^{-t / T_{\mathrm{d}}}=S_{0} \exp \left[-t \frac{T_{1}+T_{\mathrm{d}}}{T_{1} T_{\mathrm{d}}}\right]
$$

This means a faster signal decay. On the other hand, however, signal will be added according to (9):

$$
S_{\mathrm{d}}=S_{0}\left[1-e^{-t / T_{\mathrm{d}}}\right] e^{-t / T_{1}}
$$

The total signal will then be given by the sum of (8) and (9):

$$
S=S_{t}+S_{\mathrm{d}}=S_{0}\left[\exp \left[-t \frac{T_{1}+T_{\mathrm{d}}}{T_{1} T_{\mathrm{d}}}\right]+\left(1-e^{-t / T_{\mathrm{d}}}\right) e^{-t / T_{1}^{\prime}}\right]
$$

Characteristic values for the $\mathrm{Q}^{4}$ signals of Nucleosil batch no. 5061 and for the Alfa Products silica gel are summarized in Table VI. Very similar results were observed for the respective silanol signals. These are also given in Table VI.

The $T_{1}^{\prime}$ values should then be compared with the $T_{1 \mathrm{Si}}$ values as obtained by $C P$ excitation (long waiting periods) or by pulse excitation. The $T_{1}$ values of Table VI may well correspond with the short $T_{1}$ components, resulting from three-exponential analysis of relaxation times by pulse excitation (see before).

In our view, the differences in dipolar interactions between quaternary silicons and silanol protons which lead to the observed spread in ${ }^{29} \mathrm{Si}$ longitudinal relaxation rates have the same origin as variations observed in cross polarization behavior. Regions with rather high ordering (polycrystalline domains) have rather low $\mathrm{SiOH}$ mobilities because in ordered situations the possibilities of forming hydrogen bonding are higher. Lower mobilities in polycrystalline regions are then found over a rather wide frequency range, extending from $\mathrm{ca} .10^{2} \mathrm{~Hz}\left(T_{\mathrm{HSi}}\right.$ values small) via ca. $10^{5}$ $\mathrm{Hz}$ ( $T_{1 \rho \mathrm{H}}$ values) to ca. $10^{8} \mathrm{~Hz}$ ( $T_{1 \mathrm{Si}}$ values). In the more disordered, presumably amorphous regions the mobilities are higher; hydrogen bonds are less easily formed and larger values of $T_{\mathrm{HSi}}$ and longitudinal relaxation times of ${ }^{29} \mathrm{Si}\left(T_{\mathrm{ISi}}\right)$ are found. Our surmise is in agreement with the often published importance of internuclear dipolar interactions in determining ${ }^{29} \mathrm{Si} \mathrm{NMR}$ longitudinal relaxation. ${ }^{10}$ It is not, however, the only mechanism. As already suggested by Klinowski, ${ }^{14}$ paramagnetic oxygen also contributes measurably to silicon relaxation, the same is true for $\mathrm{Fe}^{3+}$ impurities (see before)

Together with the numbers for the monofunctionally derivatized materials a clear pattern emerges: upon substitution of silanols with silanes the remaining silanols relax slightly slower. A stronger trend in the same direction is noticed for the quaternary silicons. This is analogous to results described by Fyfe et al. ${ }^{6}$ The differences observed in the present study between derivatized and native silica gel are smaller than those reported by Fyfe, and the absolute values of the $T_{1}$ 's are larger. This is in agreement with a relaxation mechanism for ${ }^{29} \mathrm{Si}$ nuclei in terms of dipolar interactions with hydroxyl protons with or without invoking the influence of associated water. ${ }^{6}$ Nucleosil batch 4111 contains clearly less silanol groups than Fisher S-157 silica gel and is, in this respect, intermediate between the latter silica gel and, e.g., Porasil glass beads ${ }^{6}$ or $\mathrm{Cab}-\mathrm{O}-\mathrm{Sil}$ as reported earlier. ${ }^{15}$

In conclusion, we have demonstrated that the method of contact-time variation in CP MAS ${ }^{29} \mathrm{Si}$ NMR of silica gels yields additional information regarding the structure of the material. This information cannot be obtained in a simple way by other methods. The most probable explanation is a structure consisting of domains with clearly different mobilities in the $10^{4}-10^{9}-\mathrm{Hz}$ range. The non-single-exponential behavior of ${ }^{29} \mathrm{Si}$ longitudinal relaxation may be described similarly. Finally, cross-polarization excitation remains the method of choice for obtaining qualitatively and quantitatively meaningful ${ }^{29} \mathrm{Si}$ MAS NMR spectra of silica gels, provided due care is taken in obtaining appropriate calibration by measuring the $\mathrm{CP}$ characteristics in a number of cases. 